\title{
RNA-Mediated Transfer of the Gene coxII from the Mitochondrion to the Nucleus during Flowering Plant Evolution
}

\author{
Jacqueline $M$. Nugent" $t$ and Jeffrey D. Paimert \\ *Department of Biology \\ University of Michigan \\ Ann Arbor, Michigan 48104 \\ tDepartment of Biology \\ Indiana University \\ Bloomington, Indiana 47405
}

\section{Summary}

The gene coxll, normally present in the mitochondrion, was functionally transferred to the nucleus dur. ing flowering plant evolution. coxll transfer is estimated to have occurred between 60 and 200 million years ago, whereas loss of coxll from the mitochondrion occurred much more recently, being restricted to a single genus of legumes. Most legumes have coxll in both the nucleus and the mitochondrion; however, no evidence is found for simultaneous coxll expression in both compartments. The nuclear coxll sequence more closely resembles edited mitochondrial coxII transcripts than the genes encoding these RNAs. Hence, gene transfer appears to have involved reverse transcription of an edited RNA intermediate. The nuclear gene contains an intron at the junction of the transit peptide sequence and the mature protein-coding sequence; exon shutfling may have played a role in assembling a functional cox/l gene in the nucleus.

\section{Introduction}

The idea that some nuclear genes encoding organellar proteins are the result of evolutionary gene transfer from the organelle to the nucleus has gained wide acceptance in recent years (Shih et al., 1986; Froman et al., 1989). Evidence for ongoing gene transfer has been demonstrated for the chloroplast protein genes tufA and rp/22 (Baldauf and Palmer, 1990; J. S. Gantt, S. L. Baldauf, P. Calie, N. Weeden, and J. D. Palmer, unpublished data). Molecular and phylogenetic studies indicate that tufA was transferred to the nucleus in a green algal ancestor of land plants (at least 500 million years ago), while rp/22 transfer occurred later in a common ancestor of all flowering plants (at least $\mathbf{2 0 0}$ million years ago). In addition to these wellcharacterized gene transfers, a number of gene content differences are known among the three completely sequenced chloroplast genomes (Ohyama et al., 1986; Shinozaki et al., 1986; Hiratsuka et al., 1989); some of these differences may also reflect gene transíer.

Much less is known about the conservation of plant mitochondrial gene content, mainly due to the larger size (200$2400 \mathrm{~kb}$; Newton, 1988) and more complex organization of these organellar genomes. Variability in plant mitochondrial gene content has been demonstrated for three ribosomal protein genes (Bland et al., 1986; Bonen, 1987; Wahleithner and Wolstenholme, 1988; Schuster et al., 1990a) and for several tRNA genes (Binder et al., 1990; Bartnik and Borsuk, 1986; Izuchi et al., 1990; MaréchalDrouard et al., 1990). Members of each of these two classes of genes are found in some plant species but not in others. However, whether this variability reflects functional gene transfer to the nucleus is currently unknown.

A central question pertaining to intracellular gene transfer concerns the chemical nature of the nucleic acid molecule involved in the transfer process; are these events mediated solely by DNA or are both DNA and RNA involved? It has been suggested that some interorganellar DNA transfers may occur via an RNA intermediate, followed by local reverse transcription and genome integration (Schuster and Brennicke, 1987). So far, however, there has been little evidence to support this hypothesis; indeed, the first discovered and most dramatic case of gene transfer (albeit one without any apparent transfer of function; Stern and Lonsdale, 1982) almost certainly occurred via a strictly DNA intermediate (Nugent and Palmer, 1988). The recent discovery of plant mitochondrial RNA editing (Covello and Gray, 1989; Gualberto et al., 1989; Hiesel et al., 1989) allows for a more definitive answer to this question than was possible previously. Plant mitochondrial RNA editing involves the selective conversion of $C$ to $U$ residues (and occasionally $U$ to $C$ residues; Gualberto et al., 1990; Schuster et al., 1990b) at various positions along most if not all mRNAs and results in the production of a protein whose sequence is significantly different from that predicted from the DNA sequence. Thus, finding that the sequence of a nuclear gene, recently transferred from the mitochondrion, looks more like an edited transcript of the progenitor mitochondrial gene than the gene itself would provide strong evidence that transfer involved an RNA intermediate. Conversely, finding the transferred sequence more like the mitochondrial DNA sequence would suggest that DNA alone mediated the gene transfer event and would raise the possibility of cytoplasmic RNA editing.

We report loss of the gene cox/l from the mitochondrion within a single genus of legumes. coxll encodes subunit II of the cytochrome c oxidase complex, an essential enzyme involved in the terminal oxidative step in energy metabolism (Capaldi et al., 1983). Evidence is presented for RNA-mediated transfer of cox/l from the mitochondrion to the nucleus during flowering plant evolution.

Results

Loss of coxll from the Mitochondrion

Southern blot hybridization was used to examine mitochondrial gene content in 20 flowering plant species using probes for most known mitochondrial protein genes. Based on this survey it appears that the majority of these genes are retained in the mitochondrion over a broad taxonomic range. A striking exception to this, however, is the gene coxII. A probe internal to the soybean (Glycine max) mitochondrial coxll gene failed to hybridize to mung bean 


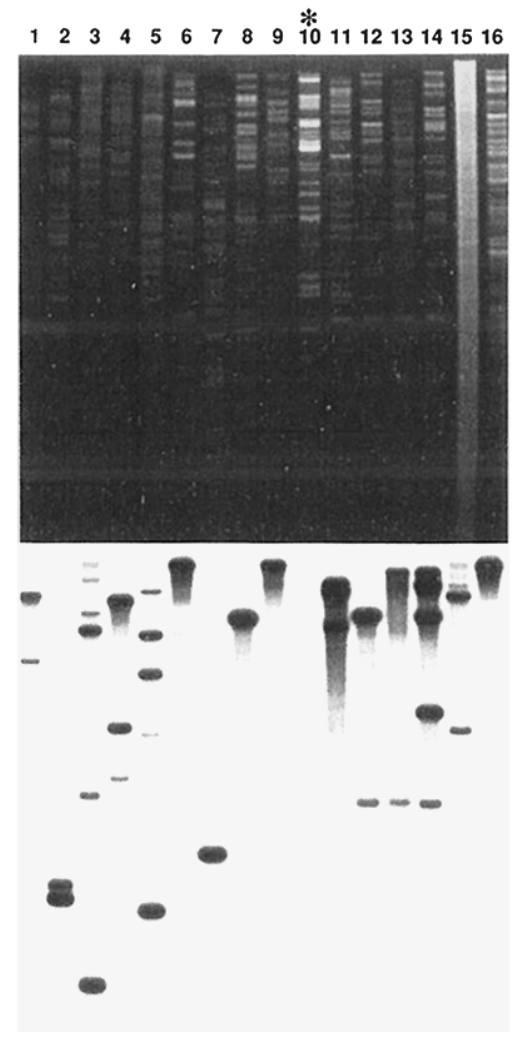

Figure 1. coxl/ Is Present in the mtDNA of All Species Examined except Mung Bean

(Top) Electrophoresis in a 1\% agarose gel of mtDNA from Triticum aestivum (wheat, lane 1, Pstl tragments), Zea mays (maize, lane 2, BamHI), Lactuca sativa (lettuce, lane 3, Xhol), Helianthus annus (sunflower, lane 4, Pstl), Lycopersicon esculentum (tomato, lane 5, BamHI), Nicotiana tabacum (tobacco, lane 6, Pst)), Oenothera johansen (evening primrose, lane 7, HindlII), Pisum sativum (pea, lane 8, Pstl), Phaseolus vulgaris (common bean, lane 9, Pstl), Vigna radiata (mung bean, lane 10, Pstl; marked by asterisk), Capsella bursa-pastoris (shepherds purse, lane 11, Pstl), Crambe abyssinica (lane 12, Pst l), Raphanus sativus (radish, lane 13, Pstl), Brassica campestris (cauliflower, lane 14, Pstl), Arabidopsis thaliana (lane 15, Pstl), and Cucurbita maxima (squash, lane 16, Pvull). Other mtDNAs included in the survey but not shown here are cucumber, watermelon, spinach, and petunia.

(Bottom) Hybridization to a filter blot of the agarose gel with a 704 bp Ncol-Hindlli fragment internal to the soybean mitochondrial cox $/$ gene.

(Vigna radiata) mitochondrial DNA (mtDNA) (Figure 1, lane 10) but hybridized strongly to all other mtDNAs examined, including those of two other legumes, pea (Pisum sativum) and common bean (Phaseolus vulgaris) (Figure 1, lanes 8 and 9). The presence of coxll in common bean mtDNA and its apparent absence from mung bean mtDNA are particularly interesting since the two species are considered closely related (indeed, were once treated as congeneric). The cox//gene loss within Vigna therefore appears to be a recent evolutionary event, having occurred since the divergence of Vigna and Phaseolus from a common ancestor.

\section{coxll in the Nucleus}

Considering the essential nature of the protein encoded

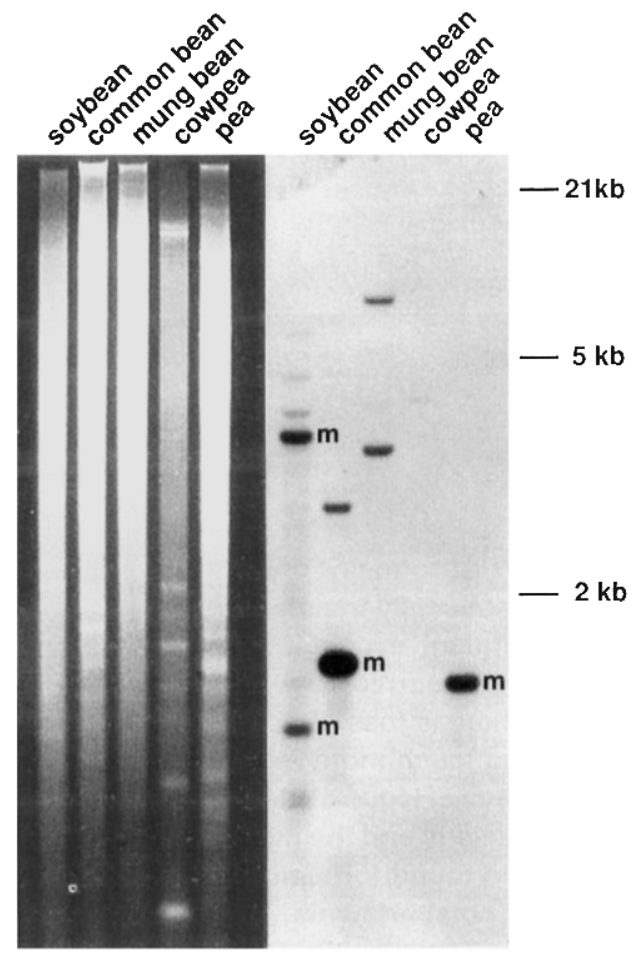

Figure 2. coxll Hybridizes to nuDNA from Five Species of Legumes Nuclear DNAs were cut with HindIII, electrophoresed in a $1 \%$ agarose gel, transferred to a nylon filter, and hybridized with the probe described in Figure 1. The signals labeled " $\mathrm{m}$ " denote hybridization to contaminating mtDNA.

by the coxll gene, it seemed unlikely that the gene had been lost entirely in mung bean and more likely that the functional gene resided in the nucleus of this species. To test this possibility, nuclear DNA (nuDNA) from mung bean and four other legumes (soybean, common bean, pea, and cowpea [Vigna unguiculata]) was probed for the presence of a coxll gene (Figure 2). Both mung bean and cowpea lack a mitochondrial cox/l gene (cowpea data not shown), whereas the three other legumes have a mitochondrial coxll gene, and consequently their nuDNA hybridization results are complicated by signals due to mtDNA contamination of the nuclear DNA preparations. These signals (marked "m," Figure 2) were diagnosed as such by parallel hybridizations to purified mtDNA (data not shown). We attribute all other signals to hybridization of cox// to nuclear DNA. The number of nuclear signals observed suggests one to two nuclear cox/l sequences in cowpea, mung bean, common bean, and pea (all diploids), and additional nuclear copies in soybean (a tetraploid; Figure 2). These results are reproducible and are supported by Southern blots using other restriction enzymes (data not shown). The weakness of the cowpea signal is attributed to underloading of this lane relative to the others (Figure 2, left). The weak nuclear signals in pea may be explained by genome size differences, the pea genome being 3-10 times larger than that of the other legumes examined (Bennett and Smith, 1976); alternatively, only part of coxII may be present in this genome. 


\section{coxII CDNA}

To examine the putative nuclear cox\| gene, clones were isolated from a cowpea cDNA library using the soybean mitochondrial cox/l gene as a probe. A polyadenylated cDNA clone was found to contain an open reading frame with $85 \%$ nucleotide sequence identity to the soybean mitochondrial cox/l gene. This reading frame is approximately 318 bp longer at its $5^{\prime}$ end than mitochondrial cox/l genes (Figure 3). If translation begins at the first of the three ATG codons within this extension, the gene would encode an $\mathrm{N}$-terminal transit peptide sequence of approximately 60 amino acids, which could function in directing the protein back to the mitochondrion. This putative transit peptide resembles other known mitochondrial transit peptides in having few negatively charged amino acids, a net positive charge, and an abundance of hydroxylated residues (von Heijne et al., 1989). The 5' sequence of mitochondrial cox/l genes differs from that of the nuclear gene, and thus the exact processing site for the mature nuclearencoded protein cannot be determined. The translation stop signal is followed by $295 \mathrm{bp}$ of sequence before the site of poly $(A)$ addition. Possible polyadenylation signals (AATAAA) are located at 196 and $74 \mathrm{bp} 5^{\prime}$ to the polyadenylation site.

The coxll-encoding region of the cDNA clone was compared with the sequences of mitochondrial cox/l genes and transcripts from four flowering plants (two monocots and two dicots). The cowpea cox/l cDNA sequence more closely resembles edited mitochondrial cox/l transcripts than the genes encoding these mRNAs (Figure 3). The mitochondrial cox/l RNA sequences are edited via $\mathrm{C}$ to $\mathrm{U}$ conversion at a combined total of 30 sites. The majority of these are fully edited sites (i.e., within a species all coxll transcripts are edited at these positions), while the remainder are partially edited sites (i.e., within a species these positions are edited in some cox/l transcripts but not others). Twenty-three of these 30 editing sites contain a $T$ in the cowpea cDNA sequence. This result suggests two alternative scenarios, both of which have intriguing implications: the cowpea cDNA clone was derived from an edited nuclear cox/l transcript; or an edited version of the cox/l gene is present in the cowpea nuclear genome.

\section{Nuclear cox/I Gene}

Oligonucleotide primers complementary to $5^{\prime}$ and $3^{\prime}$ regions of the sequenced cDNA clone were used to amplify with the polymerase chain reaction (PCR) the nuclear coxll gene from cowpea total DNA. The genomic and CDNA sequences are in complete agreement (data not shown), implying that an edited version of the cox/l gene is present in the cowpea nucleus.

The cowpea cox/l gene has a typical nuclear intron (Breathnach and Chambon, 1981), 740 bp in length, located at or near the junction of the putative transit peptide sequence and the mature protein-coding sequence. The alignment presented in Figure 3 places the intron within what is perhaps the first codon of the mature cox/l protein. However, this placement is speculative since the precise junction of the transit and mature polypeptides is not known.

\section{Timing of cox $\|$ Transfer to the Nucleus}

To address the timing of the cox/l gene transfer event, we constructed a phylogeny of eight sequenced coxll genes (including the cowpea nuclear cox/l gene) and compared this with an independent "organismal" phylogeny (based on morphological data and chloroplast $r b c L$ sequence data) for the same eight species (Figure 4). The organismal phylogeny places cowpea closer to soybean than to any of the other species included in this analysis (Figure 4A). If the gene transfer were a recent evolutionary event that had taken place not long before the loss of coxll from the mitochondrion in Vigna, we would expect the gene phylogeny to mirror the organismal phylogeny, i.e., the cowpea nuclear sequence should be placed closer to the soybean mitochondrial sequence than to any of the other mitochondrial sequences in the analysis. In fact, however, a phylogenetic tree derived from a distance analysis of nucleotide sequences (Figure 4B) places the cowpea nuclear gene on a very long branch outside the legume mitochondrial lineage as defined by pea and soybean, members of two distantly related tribes in the legume subfamily Papilionoideae. The bootstrap value supporting the pea/ soybean node on this tree is $100 \%$.

This result suggests that transfer of coxll to the nucleus predated the divergence of the sublamily Papilionoideae. This would place the timing of the transfer event between 60 and 200 million years ago, before the emergence of the Papilionoideae but since the divergence of the monocots and dicots (Crepet and Taylor, 1985; Wolfe et al., 1989b). The nine shortest trees yielded by a parsimony analysis (data not shown) using the same nucleotide sequences all placed cowpea outside soybean and pea, as in the distance analysis. However, three of these nine trees also placed Oenothera as the closest relative to pea, a clearly anomalous result that may be related to an accelerated mutation rate in Oenothera relative to the other mitochondrial coxll sequences (note the long Oenothera branch length in Figure 4B). Excluding Oenothera from the parsimony analysis gave a single shortest tree (data not shown) that was in agreement with the distance tree presented here, with the pea/soybean node supported by a bootstrap value of $94 \%$. Parsimony analysis using deduced amino acid sequences gave the same result.

\section{cox/l Expression in Legumes}

Southern blot and phylogenetic data suggest that coxll might be present in both the mitochondrial and nuclear genomes of most legumes. Northern blot hybridizations were therefore carried out to determine which genes are expressed-mitochondrial, nuclear, or both. A soybean mitochondrial cox/l probe reveals a $1.3 \mathrm{~kb}$ transcript in cowpea that is substantially enriched in poly $(A)^{+}$RNA and absent from mtRNA (Figure 5B). This result indicates that coxII mRNA is solely the product of a nuclear gene in cowpea and is consistent with the gene distribution data (Figure 6). The published sequence of the soybean mitochondrial cox/lgene predicts a functional gene with $97.7 \%$ sequence identity to the pea mitochondrial coxll gene (Grabau, 1987). Northern blot results, however, suggest that only the nuclear cox/l gene(s) in soybean is ex- 


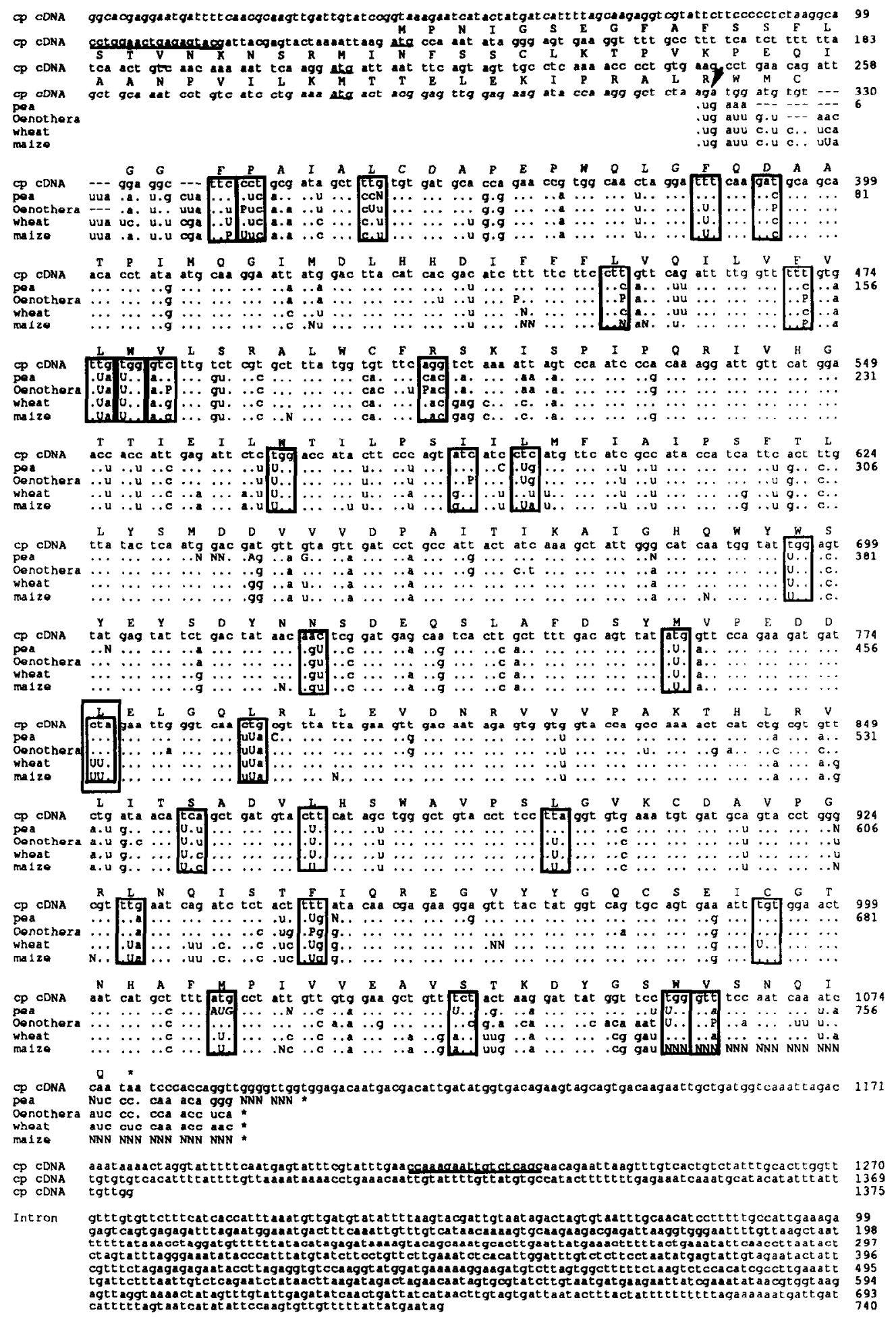

Figure 3. The Cowpea cox// CDNA Sequence More Closely Resembles Edited Mitochondrial cox/l Transcripts Than the Genes Encoding These RNAS

The cowpea cox/l cDNA (cp cDNA) sequence is aligned with edited mitochondrial cox/l transcripts from pea, Oenothera, wheat, and maize. The pea, maize, and wheat sequences are taken from Covello and Gray (1990) and the Oenothera sequence from Hlesel et al. (1990). A total of 30 positions are edited via $\mathrm{C}$ to $\mathrm{U}$ conversion in these transcripts (boxed regions; a codon containing two edited nucleotides is double-boxed). A single edited site in maize (within the fifth codon) is omitted from the analysis as it corresponds to a codon deletion in pea and cowpea. A single site in Oenothera is partially edited via $U$ to $C$ conversion (corresponds to position 124 in pea). Capital letters indicate differences between the RNA sequences and the corresponding published DNA sequences: (U) denotes fully edited sites, uridine in RNA corresponds to cytidine in DNA; $(P)$ denates partially edited sites; and (N) denotes undetermined RNA sequence. Nucleotide positions 273, 323, 328, 475, and 694-696 in pea represent unconfirmed differences between the DNA and RNA sequences (for explanation see Covello and Gray, 1990). identical residues between sequences are denoted by dots; gaps are denoted by dashes. Three potential translational start sites (ATG) that are in frame with and upstream of the cowpea 
A.

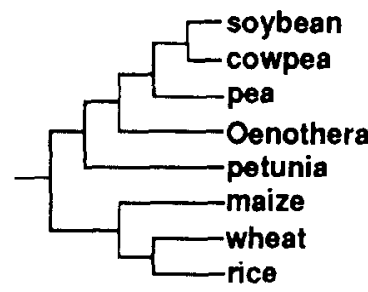

B.

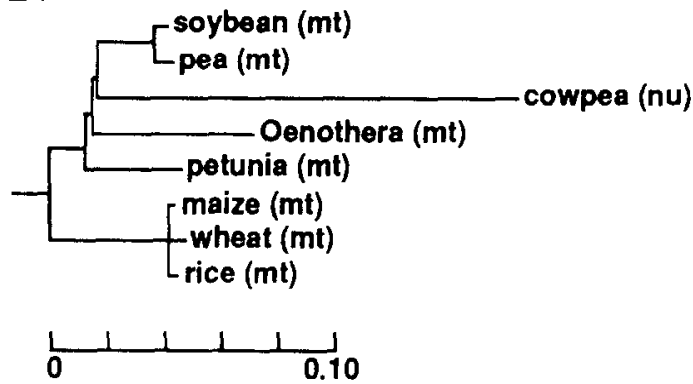

Figure 4. cox/IWas Transferred to the Nucleus in a Common Ancestor of the Legume Subtamily Papilionoideae

(A) Organismal phylogeny based on morphological data (Cronquist, 1988; Donoghue and Doyle, 1989) and chloroplast $r b c L$ sequence data (R. Olmstead, K. Sytsma, and J. Palmer, unpublished data). (B) Phylogenetic tree derived from distance analysis of cox/l DNA sequence data. Mitochondrial sequences were taken from Fox and Leaver (1981) (maize); Hiesel and Brennicke (1983) (Oenothera); Bonen et al. (1984) (wheat); Kao et al. (1984) (rice); Moon et al. (1985) (pea); Grabau (1987) (soybean); and Pruitt and Hanson (1989) (petunia). The tree was constructed by the method of Olson (1988a, 1988b) and is rooted using the monocots as the outgroup. Horizontal branches are drawn proportional to length; the scale bar below the tree indicates extent of sequence divergence. Positions known to be edited in any species were excluded from the analysis

pressed. A transcript of approximately $1.2 \mathrm{~kb}$ is observed in the soybean poly $(A)^{+} \mathrm{RNA}$ lane, no transcript is detected in the poly $(A)^{-}$RNA lane, and only a faint broad smear (with "ghost" areas in regions of rRNA bands) is seen in the mtRNA lane. Part of the coxll gene is known to be repeated within the soybean mitochondrial genome, and it is possible that this hybridization smear is the result of transcription through this region (Grabau, 1987). In common bean the mitochondrial cox/l gene is also silent and only the nuclear gene(s) is expressed (data not shown; Figure 6). Conversely, in pea the mitochondrial gene is expressed and the nuclear cox// sequences are silent (Figure $5 B$ ). Rehybridization of the same filter with a pea probe specific for the nuclear H-protein gene (encoding the smallest subunit of the mitochondrial glycine decarboxylase complex; Kim and Oliver, 1990) demonstrates that a nuclear transcript can be readily detected in the pea poly $(A)^{+}$RNA lane (Figure $5 \mathrm{C}$ ).

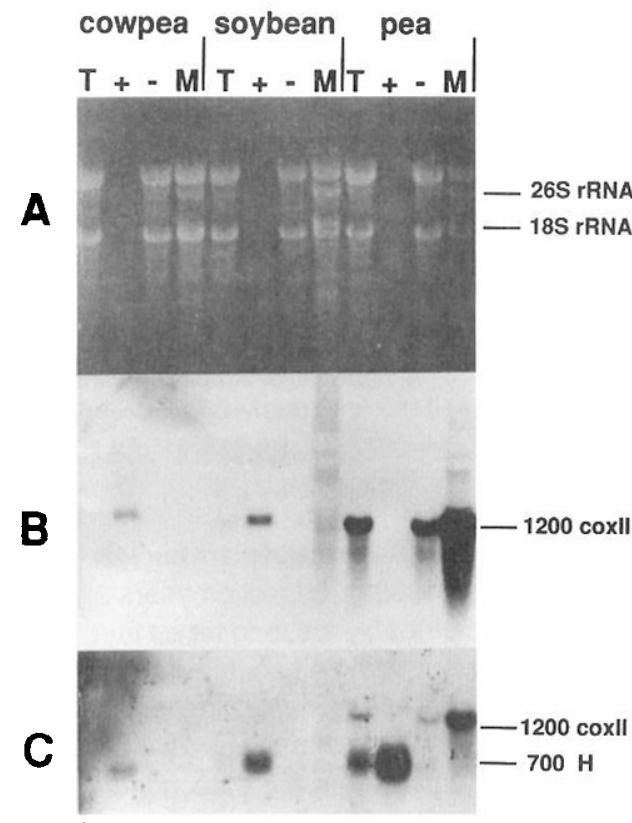

Figure 5. cox/l Is Expressed in the Nucleus of Cowpea and Soybean but in the Mitochondrion of Pea

(A) Electrophoresis in a $1.2 \%$ agarose gel of total RNA (T), poly(A) RNA (+), poly(A)- RNA (-), and mitochondrial RNA (M) from cowpea, soybean, and pea.

(B) Hybridization to a filter blot of the RNA gel with the soybean mitochondrial coxl/ probe described in Figure 1.

(C) The Northern blot was stripped and rehybridized with a probe specific for the nuclear $\mathrm{H}$-protein gene (encoding the smallest subunit of the mitochondrial glycine decarboxylase complex). cox/l signals in this panel represent carryover from the previous cox/l hybridization.

\section{Discussion}

\section{Differential Timing of Events in Gene Transfer}

Transfer of a functional cox/l gene to the nucleus can be resolved into at least three temporally distinct phases (Figure 6): physical transfer of the gene to the nucleus; activation of the nuclear gene and concomitant inactivation of the mitochondrial gene; and loss of the mitochondrial gene. Phylogenetic analyses indicate that physical transfer of the cox/lgene to the nucleus occurred 60-200 million years ago, after the emergence of the monocots and dicots, but before the origin of the legume subfamily Papilionoideae. This finding is supported by Southern blot data showing nuclear cox//sequences in a broad range of species within the Papilionoideae. The nuclear cox//gene represents the most recent example of organellar gene transfer known. The two other well-characterized cases of "modern" gene transfer both involve chloroplast genes that were transferred to the nucleus before the emergence of flowering plants (Baldauf and Palmer, 1990; Gantt et al. unpublished data).

cox 1 -coding region are underlined. Nucleotide 1375 is followed by a poly(A) tract in the cowpea cDNA. The amino acid sequence inferred from the CDNA is denoted by the single-letter code above the cDNA sequence. Underlined 18-mer oligonucleotides in the $5^{\prime}$ and $3^{\prime}$ untranslated regions of the cDNA sequence indicate sequences of primers used to PCR amplify the cowpea nuclear cox/l gene. The arrow between positions 320 and 321 in the cowpea sequence indicates the location of a $740 \mathrm{bp}$ intron present in the PCR-amplified nuclear cox/l gene. The intron sequence is presented below the sequence alignments. 


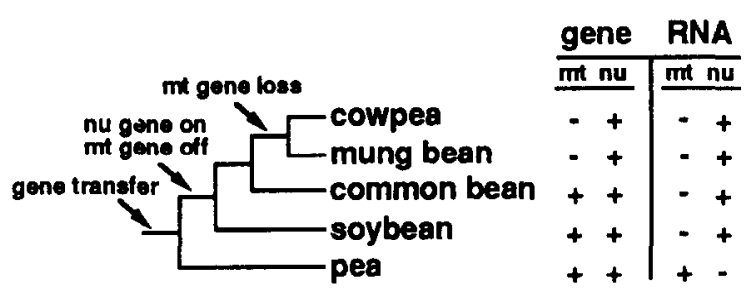

Figure 6. Schematic Representation of Timing of Events In Functional cox/l Gene Transfer during Angiosperm Evolution

Organismal phylogeny is derived from morphological data (reviewed in Polhill, 1981). The table on the right denotes the cellular distribution of coxl genes and indicates which genes are being expressed.

Given the relatively fast rate of plant nuclear gene evolution (Wolfe et al., 1989a), 60 million years (minimum for gene transfer) is probably too long for an inactive gene to reside in the nucleus without becoming so highly mutated as to lose potential functionality. Indeed, Northern blot results (Figure 5) indicate that the nuclear cox/l gene was active for some time before the mitochondrial gene was lost in the lineage leading to Vigna. As summarized in Figure 6, activation of the nuclear gene and inactivation of the mitochondrial gene occurred after the divergence of the lineage leading to pea but prior to the divergence of the lineages leading to soybean and common bean.

Presumably, before mitochondrial gene loss can occur, both the mitochondrial and nuclear genes must be expressed within the same lineage for at least a short period of time. However, despite apparent coexistence of nuclear and mitochondrial cox//genes in several lineages (Figures 2 and 6), Northern blot experiments show no evidence of dual mitochondrial and nuclear coxll expression in legumes (Figure 5). coxll expression needs to be examined in additional legumes, of phylogenetic relationship corresponding to the apparent switchpoint in mitochondrial to nuclear expression, to determine more precisely when this switch may have occurred. Dual expression cannot, however, be totally discounted from our current results. For example, posttranscriptional regulation may cause either a mitochondrial or nuclear coxl/ transcript to be degraded rapidly. Alternatively, coxll expression may be developmentally regulated in either the mitochondrion or the nucleus; investigation of different developmental stages may produce evidence of simultaneous nuclear and mitochondrial cox/l transcription within these species.

The nuclear coxll gene is evolving considerably faster, at both nucleotide (Figure 4B) and amino acid sequence levels (data not shown), than mitochondrial coxll genes. This acceleration at both levels may be largely, if not entirely, due to mutation pressures in the nucleus that are 12-fold greater than in the mitochondrion (Wolfe et al., 1989a). In addition, it is possible that some amino acid changes, e.g., those aiding transport of the protein through the cytoplasm and across the mitochondrial membrane, have been selected for since the nuclear gene became functional.

Gene Activation Mechanism

For transferred genes to become functional, several se- quences must be acquired, including transcription and translation signals as well as an $\mathrm{N}$-terminal transit peptide sequence to direct the protein back to the organelle. The nuclear cox/l gene has acquired two sequences since its transfer from the mitochondrion: a putative transit peptide-encoding domain and an intron that appears to divide the gene into one exon encoding this transit peptide and a second exon encoding the mature cox/l protein. It is tempting to speculate that the intron was instrumental in establishing a functional cox//gene in the nucleus by promoting recombination events in the region upstream of the transferred gene, resulting in recruitment of expression sequences and the transit peptide sequence - in essence, that the nuclear gene was assembled by a form of exon shuffling (Gilbert, 1978). Several other nuclear genes, encoding either mitochondrial or chloroplast proteins, also have introns located at transit peptide/mature polypeptide junctions (Tsuzuki et al., 1987; Takeshima et al., 1988; Gantt et al., unpublished data).

\section{Gene Transfer Mechanism}

The existence of extensive RNA editing in plant mitochondria has allowed us to make a compelling argument for the involvement of an RNA intermediate in intracellular gene transfer. This is based on the striking sequence similarity of the cowpea nuclear cox/l gene to edited mitochondrial coxll transcripts rather than to mitochondrial cox/l genes. Twenty-three of a combined total of 30 positions known to be edited via $\mathrm{C}$ to $\mathrm{U}$ conversion in several mitochondrial cox/l transcripts have the "edited" nucleotide equivalent in cowpea. A total of 15 edited positions are common to both monocot and dicot mitochondrial cox// transcripts, indicating that plant mitochondrial RNA editing predates the emergence of monocots and dicots. Since phylogenetic studies indicate that cox// gene transfer occurred after the divergence of monocots and dicots (Figure 4B) we can conclude that gene transfer occurred after the advent of mitochondrial RNA editing in flowering plants.

Gene transfer involving an edited RNA intermediate is therefore the likely scenario, since transfer involving DNA alone would necessitate many changes in the nuclear sequence before the establishment of a functional gene. At least eight fully edited positions in mitochondrial cox/l transcripts may represent essential alterations of the RNA molecule. These editing events change the amino acid specificity of a codon, are observed in all mitochondrial cox/l transcripts examined to date (Figure 3), and the edited nucleotide equivalent is found at all eight positions in the cowpea nuclear gene. At the very least, therefore, a DNAmediated transfer event would likely require mutations at these eight positions in the nuclear cox// sequence before a potentially functional gene could be achieved. It is difficult to envision how such selective changes could occur in the absence of any obvious selection pressure, since until such time as a functional gene is established in the nucleus, a functional gene must also be maintained in the mitochondrion. One possibility is that these changes have occurred as a result of general enzymatic deamination of 5-methylcytosine to thymine in the nuDNA sequence, similar to the RIP process that occurs in some filamentous 


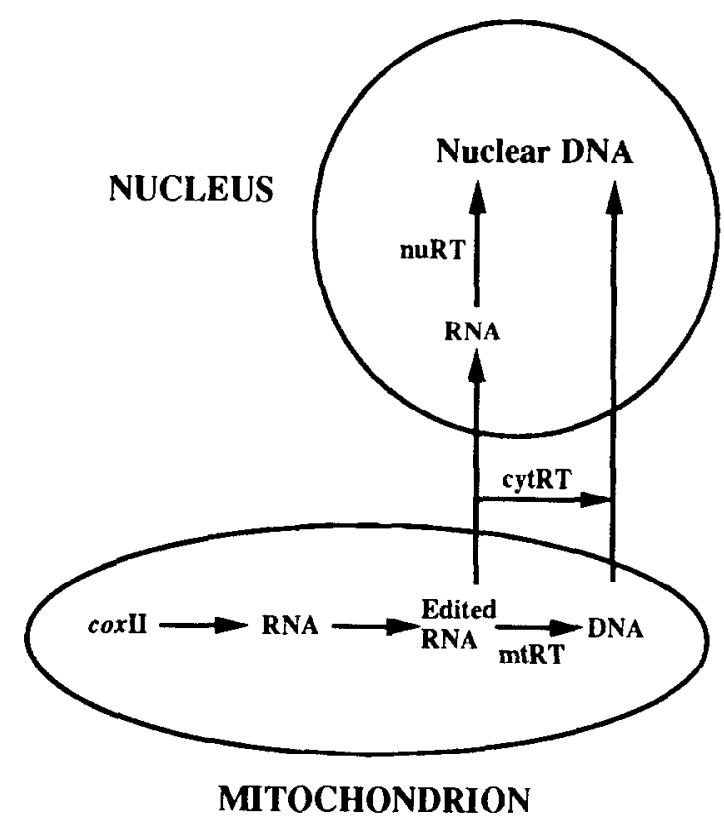

Figure 7. Several Avenues of Gene Transfer Involving an Edited RNA Intermediate May Be Possible within Plant Cells

mtRT, mitochondrial reverse transcriptase; cytRT, cytoplasmic reverse transcriptase; nuRT, nuclear reverse transcriptase.

ascomycetes (Selker, 1990). In this case one would expect

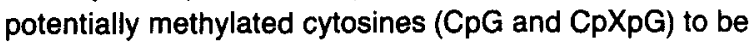
much rarer in the nuclear coxl/ sequence than in a corresponding mitochondrial sequence; in fact, however, mitochondrial cox/l sequences and the cowpea nuclear coxll sequence contain similar numbers of potentially methylated cytosines (e.g, 35 and 37 for Oenothera and cowpea, respectively).

Figure 7 shows several possible avenues of gene transfer mediated by an RNA molecule. All of these involve a reverse transcription step but differ by where in the cell this step takes place and by the type of molecule that is transferred across membranes. In one scheme reverse transcription occurs in the mitochondrion and a DNA copy of the gene is transferred to the nucleus. In alternative schemes, an edited RNA molecule leaves the mitochondrion, is reverse transcribed in either the cytoplasm or the nucleus, and a DNA copy is subsequently incorporated by the nuclear genome. Reverse transcriptase-like sequences have been found in several plant mitochondrial genomes (Schuster and Brennicke, 1987; Wahleithner et al., 1990), and the existence of processed pseudogenes in plant nuclear genomes (Drouin and Dover, 1987) suggests that reverse transcriptase activity is also present in the cytoplasm and/or nucleus. Thus, plant cells could contain the reverse transcriptases necessary to facilitate any of the pathways outlined in Figure 7. Other examples of expressed genes derived by retrotransposition (but not involving intracellular gene transfer) have been found in mammals and include the preproinsulin I gene (Soares et al., 1985), the Pgk-2 gene (McCarrey and Thomas, 1987; Boer et al., 1987), and the Pdha-1 gene (Dahl et al., 1990).

It is possible that all successful transfers of plant mito- chondrial genes to the nucleus have involved an edited RNA intermediate. This transfer mechanism precludes the necessity for specific DNA mutations to restore the universal genetic code and may allow for the more rapid establishment of a functional transferred gene in the nucleus. One prediction from this is that successful gene transfers may occur more readily for plant mitochondria than for either animal or fungal mitochondria, which use nonuniversal genetic codes and appear not to employ RNA editing.

\section{Experimental Procedures}

Nucleic Acid Preparations

mtDNAs were isolated from either green leaves or etiolated seedlings according to the DNAase I procedure of Kolodner and Tewari (1972). Total DNA was isolated from green leaves by the CTAB isolation procedure of Doyle and Doyle (1987).

Nuclear DNA was prepared from etiolated seedlings by the procedure of Watson and Thompson (1986). Total RNA was prepared from etiolated shoot tissue according to a scaled-up version of the guanidinium isothiocyanate extraction procedure described by Hamby et al. (1988). Poly(A) ${ }^{+}$RNA was fractionated by batch procedure using oligo(dT)-cellulose (type 3, Collaborative Research Inc.) as described by Jacobson (1987). mtRNA was prepared according to the method of Stern and Newton (1988); after lysis of the mitochondria the RNA was pelleted through a cushion of $5.7 \mathrm{M} \mathrm{CsCl}$ solution, and the remaining treatments were as described by Hamby et al. (1988) for total RNA preparation.

\section{Southern/Northern Blots}

DNAs were electrophoresed through $1 \%$ agarose gels before transfer to Zetabind membranes by standard blotting procedures (Maniatis et al., 1982). The membranes were prehybridized and hybridized at $60^{\circ} \mathrm{C}$ in Blotto solution (0.5\% nonfat dry milk, $1 \%$ SDS, $4 \times$ SSC, preheated to $60^{\circ} \mathrm{C}$ ). Following hybridization, the filters were washed in $2 \times S S C$, $0.5 \%$ SDS (three $5 \mathrm{~min}$ washes at room temperature followed by three 30 min washes at $60^{\circ} \mathrm{C}$ ). RNA was electrophoresed through a $1.2 \%$ agarose gel after denaturation with glyoxal and dimethyl sulfoxide (Sambrook et al., 1989) and transferred to Zetabind membranes. Filters were prehybridized and hybridized at $65^{\circ} \mathrm{C}$ in $5 \%$ SDS, $10 \%$ dextran sulfate, and $1 \mathrm{M} \mathrm{NaCl}$. Following hybridization, filters were washed in $2 \times$ SSC, $0.5 \%$ SDS as described above (high temperature wash $65^{\circ} \mathrm{C}$ ). Hybridization probes were labeled using random oligonucleotide primers (Sambrook at al., 1989); for Northern blots unincorporated nucleotides were removed by passing the probe over a Sephadex G-50 column

\section{CDNA and Genomic coxll Gene}

A cowpea cDNA library, constructed in the $\lambda$ Zap cloning vector (Stratagene), was provided by Dr. Narendra Singh and Dr. Ray Bressan. The library was screened by plaque hybridization on nitrocellulose filters with a 704 bp Ncol-HindIII fragment internal to the soybean mitochondrial cox/l gene (Grabau, 1987). This fragment was subcloned from a $3.5 \mathrm{~kb}$ Hindlll clone provided by Dr. Elizabeth Grabau. Hybridization conditions were as described for Southern blots. The genomic coxll gene was amplified using Taq polymerase-mediated PCR. Two synthetic 18-mer oligonucleotides were designed for use as amplification primers based on the $5^{\prime}$ and $3^{\prime}$ sequence of the CDNA clone (positions 100-117 and 1214-1231; Figure 3). Within the $3^{\prime}$ primer the sequence GAATTG was changed to GAATTC, creating an EcoRI restriction site. All sequencing was by the dideoxynucleotide chain termination method (Sanger et al., 1977) using a combination of synthetic oligonucleotide primers and a series of nested deletions created by exonuclease IIl digestion (Erase-A-Base, Promega). All DNAs were sequenced completely on both strands.

\section{Computer Analyses}

Nucleotide sequences were analyzed using the distance matrix program developed by Olsen (1988a, 1988b) and by maximum parsimony, using the exhaustive search option (branch and bound) of PAUP 3.0 (David Swofford, Illinois Natural History Survey, Champaign, IL). Maxi- 
mum parsimony analysis was also used to analyze deduced amino acid sequences. Edited positions were excluded from all analyses. Bootstrap analysis (Felsenstein, 1985) was performed to assess the relative support of clades identified by both parsimony and distance 100 replications were used for distance analysis and 1000 replications for maximum parsimony analysis

\section{Acknowlegments}

We gratefully acknowlege R. Bressan and N. Singh for providing us with the cowpea cDNA library, E. Grabau for the soybean mitochondria cox/l gene probe, D. Oliver for the $\mathrm{H}$-protein gene probe, and M. Hanson, $K$. Newton, and B. Sears tor providing several of the mtDNAs used in Figure 1. We thank $S$. Barns and $C$. Turbeville for computer assistance, $\mathrm{S}$. Baldauf and $\mathrm{K}$. Wolfe for critically reading the manuscript, P. Pukkila for helpful discussion, and two anonymous reviewers for helpful comments. This work was supported by NIH grant GM-35087 to J. D. P. and a Midwest Biotechnology Consortium Fellowship to J. M. N

The costs of publication of this article were defrayed in part by the payment of page charges. This article must therefore be hereby marked "advertisement" in accordance with 18 USC Section 1734 solely to indicate this fact.

Received April 29, 1991; revised June 7, 1991

\section{References}

Baldauf, S. L., and Paimer, J. D. (1990). Evolutionary transfer of the chloroplast tufA gene to the nucleus. Nature 344, 262-265

Bartnik, E., and Borsuk, P. (1986). A glycine tRNA gene from lupine mitochondria. Nucl. Acids Res. 14, 2407.

Bennett, M. D., and Smith, J. B. (1976). Nuclear DNA amounts in angiosperms. Phil. Trans. Roy. Soc. (Lond.) B 274, 227-274.

Binder, S., Schuster, W., Grienenberger, J.-M., Weil, J.-H., and Brennicke, A (1990). Genes for tRNA ${ }^{\text {Gly }}$, tRNA ${ }^{\text {His }}$, tRNA ${ }^{\text {Phe }}$, tRNA $^{\text {Ser }}$ and tRNA ${ }^{\text {Tyr }}$ are encoded in Oenothera mitochondrial DNA. Curr. Genet. 17, 353-358

Bland, M. M., Levings, C. S., III, and Matzinger, D. F. (1986). The tobacco mitochondrial ATPase subunit 9 gene is closely linked to an open reading frame for a ribosomal protein. Mol. Gen. Genet. 204, 8-16.

Boer, P. H., Adra, C. N., Lau, Y.-F., and McBurney, M. W. (1987). The testis-specific phosphoglycerate kinase gene $p g k$-2 is a recruited retroposon. Mol. Cell. Biol. 7, 3107-3112.

Bonen, L. (1987). The mitochondrial $S 13$ ribosomal protein gene is silent in wheat embryos and seedlings. Nucl. Acids Res. 15, 1039310404.

Bonen, L., Boer, P. H., and Gray, M. W. (1984). The wheat cylochrome oxidase subunit II gene has an intron insert and three radical amino acid changes relative to maize. EMBO J. 3, 2531-2536.

Breathnach, R., and Chambon, P. (1981). Organization and expression of eukaryotic split genes coding for proteins. Annu. Rev. Biochem. $50,349-383$.

Capaldi, R. A., Malatesta, F., and Darley-Usmar, V. M. (1983). Structure of cytochrome c oxidase. Biochim. Biophys. Acta 726, 135-148. Covello. P. S. and Gray, M. W. (1989). RNA editing in plant mitochondria. Nature 341, 662-666.

Covello, P. S., and Gray, M. W. (1990). Differences in editing at homologous sites in messenger RNAs from angiosperm mitochondria. Nucl Acids Res. 18, 5189-5196.

Crepet, W. L., and Taylor, D. W. (1985). The diversification of the Leguminosae: first fossil evidence of the Mimosoideae and Papilionoideae. Science 228, 1087-1089.

Cronquist, A. (1988). The Evolution and Classification of Flowering Plants, Second Edition (New York: The New York Botanical Garden). Dahl, H. H. M., Brown, R. M., Hutchison, W. M., Maragos, C., and Brown, G. K. (1990). A testis-specific form of the human pyruvate dehydrogenase E1a subunit is coded for by an intronless gene on chromosome 4. Genomics 8, 225-232.
Donoghue, M. J., and Doyle, J. A. (1989). Phylogenetic studies of seed plants and angiosperms based on morphological characters. In The Hierarchy of Life: Molecules and Morphology on Phylogenetic Analysis (Amsterdam, New York, Oxford: Elsevier Science Publishers), pp. $181-193$

Doyle, J. J., and Doyle, J. L. (1987). A rapid isolation procedure for small quantities of fresh leaf tissue. Phytochem. Bull. 19, 11-15.

Drouin, G., and Dover, G. A. (1987). A plant processed pseudogene. Nature 328, 557-558.

Felsenstein, J. (1985). Confidence limits on phylogenies: an approach using bootstrap. Evolution 39, 783-791.

Fox, T. D., and Leaver, C. J. (1981). The Zea mays mitochondrial gene coding cytochrome oxidase subunit II has an intervening sequence and does not contain TGA codons. Cell 26, 315-323.

Froman, B. E., Tait, R. C., and Gottlieb, L. D. (1989). Isolation and characterization of the phosphoglucose isomerase gene from Escherichia coli. Mol. Gen. Genet. 217, 126-131.

Gilbert, W. (1978). Why genes in pieces? Nature 271, 501.

Grabau, E (1987) . Cytochrome oxidase subunit Il gene is adjacent to an initiator methionine tRNA gene in soybean mitochondrial DNA. Curr. Genet. 11, 287-293.

Gualberto, J., Lamattina, L., Bonnard, G., Weil, J.-H., and Grienenberger, J.-M. (1989). RNA editing in wheat mitochondria results in the conservation of protein sequences. Nature 341, 660-662

Gualberto, J. M., Weil, J.-H., and Grienenberger, J.-M. (1990). Editing of the wheat coxllI transcript: evidence for twelve $C$ to $U$ and one $U$ to $\mathrm{C}$ conversions and for sequence similarities around editing sites. Nucl. Acids Res. 18, 3771-3776.

Hamby, R. K. Sims, L. E., Issel, L. E., and Zimmer, E. A. (1988). Direct ribosomal RNA sequencing-optimization of extraction and sequencing methods for work with higher plants. Plant Mol. Biol. Rep. 6, 175192.

Hiesel, R., and Brennicke, A. (1983). Cytochrome oxidase subunit II gene in mitochondria of Oenothera has no intron. EMBO J. 2, 21732178

Hiesel, R., Wissinger, B., Schuster, W., and Brennicke, A. (1989). RNA editing in plant mitochondria. Science $246,1632-1634$

Hiesel, R., Wissinger, B., and Brennicke, A. (1990). Cytochrome oxidase subunit II mRNAs in Oenothera mitochondria are edited at 24 sites. Curr. Genet. 18, 371-375.

Hiratsuka, J., Shimada, H., Whittier, R. F., Ishibashi, T., Sakamoto M., Mori, M., Kondo, C., Honji, Y., Sun, C.-R., Meng, B.-Y., Li, Y.-Q. Kanno, A., Nishizawa, Y., Hirai, A., Shinozaki, K., and Sugiura, M. (1989). The complete sequence of the rice (Oryza sativa) chloroplast genome: intermolecular recombination between distinct tRNA genes accounts for a major plastid DNA inversion during the evolution of the cereals. Mol. Gen. Genet. 217, 185-194.

Izuchi, S., Teracji, T., Sakamoto, M., Mikami, T., and Sugita, M. (1990) Structure and expression of tomato mitochondrial genes coding for tRNA $^{\text {Cys }}$ (GCA), tRNA ${ }^{\text {Asn }}$ (GUU) and tRNA ${ }^{\text {Tyr }}$ (GUA): a native tRNA ${ }^{\text {Cys }}$ gene is present in dicot plants but absent in monocot plants. Curr Genet. 18, 239-243.

Jacobson, A. (1987). Purification and fractionation of poly(A)+ RNA Meth. Enzymol. 152, 254-261.

Kao, T., Moon, E., and Wu, R. (1984). Cytochrome oxidase subunit It gene of rice has an insertion sequence within the intron. Nucl. Acids Res. 12, 7305-7315.

Kim, Y., and Oliver, D. J. (1990). Molecular cloning, transcriptiona characterization, and sequencing of cDNA encoding the $\mathrm{H}$-protein of the mitochondrial glycine decarboxylase complex in peas. J. Biol. Chem. 265, 848-853

Kolodner, R., and Tewari, K. K. (1972). Physiochernical characteriza tion of mitochondrial DNA from pea leaves. Proc. Natl. Acad. Sci. USA $69,1830-1834$

Maniatis, T., Fritsch, E. F., and Sambrook, J. (1982). Molecular Cloning: A Laboratory Manual. (Cold Spring Harbor, New York: Cold Spring Harbor Laboratory)

Maréchal-Drouard, L., Guillemaut, P., Cosset, A., Arbogast, M. 
Weber, F., Weil, J.-H., and Dietrich, A. (1990). Transfer RNAs of potato (Solanum tuberosum) mitochondria have different genetic origins. Nucl. Acids Res. 18, 3689-3696.

McCarrey, J. R., and Thomas, K. (1987). Human testis-specific PGK gene lacks introns and possesses characteristics of a processed gene. Nature 326, 501-505.

Moon, E., Kao, T., and Wu, R. (1985). Pea cytochrome oxidase subunit Il gene has no intron and generates two mRNA transcripts with different 5'-termini. Nucl. Acids Res. 13, 3195-3212.

Newton, K. J. (1988). Plant mitochondrial genomes: organization, expression and variation. Annu. Rev. Plant Physiol. Plant Mol. Biol. 39, 503-532.

Nugent, J. M., and Palmer, J. D. (1988). Location, identity, amount and serial entry of chloroplast DNA sequences in crucifer mitochondrial DNAs. Curr. Genet. 14, 501-509.

Ohyama, K., Fukuzawa, H., Kohchi, T., Shirai, H., Sano, T., Sano, S., Umesono, K., Shiki, Y., Takeuchi, M., Chang, Z., Aota, S.-I., Inokuchi, $H$. and Ozeki, H. (1986). Chloroplast gene organization deduced from complete sequence of liverwort Marchantia polymorpha chloroplast DNA. Nature 322, 572-574.

Olsen, G. J. (1988a). The earliest phylogenetic branchings: comparing rRNA-based evolutionary trees inferred with various techniques. Cold Spring Harbor Symp. Quant. Biol. 52, 825-838.

Olsen, G. J. (1988b). Phylogenetic analysis using ribosomal RNA Meth. Enzymol. 164, 793-812.

Polhill, R. M. (1981). Papilionoideae. In Advances in Legume Systematics, R. M. Polhill and P. H. Raven, eds. (Kew, England: Royal Botanic Gardens), pp. 191-208.

Pruitt, K. D., and Hanson, M. R. (1989). Cytochrome oxidase subunit II sequences in Petunia mitochondria: two intron-containing genes and an intron-less pseudogene associated with cytoplasmic male sterility. Curr. Genet 16, $281 \cdot 291$

Sambrook, J., Fritsch, E. F., and Maniatis, T. (1989). Molecular Cloning: A Laboratory Manual, Second Edition (Cold Spring Harbor, New York: Cold Spring Harbor Laboratory)

Sanger, F., Nicklen, S., and Coulson, A. R. (1977). DNA sequencing with chain-terminating inhibitors. Proc. Natl. Acad. Sci. USA 74, 54635467.

Schuster, W., and Brennicke, A. (1987). Plastid, nuclear and reverse transcriptase sequences in the mitochondrial genome of Oenothera: is genetic information transferred between organelles via RNA? EMBO J. 6, 2857-2863.

Schuster, W., Wissinger, B., Unseld, M., and Brennicke, A. (1990a) Transcripts of the NADH-dehydrogenase subunit 3 gene are differentially edited in Oenothera mitochondria. EMBO J. 9, 263-269.

Schuster, W., Hiesel, R., Wissinger, B., and Brennicke, A. (1990b)

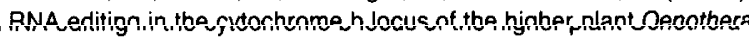
berteriana includes a C-to-U transition. Mol. Cell. Biol. 10, 2428-2431.

Selker, E. U. (1990). Premeiotic instability of repeated sequences in Neurospora crassa. Annu. Rev. Genet. 24, 579-613.

Shih, M.-C., Lazar, G., and Goodman, H. M. (1986). Evidence in favor of the symbiotic origin of chloroplasts: primary structure and evolution of tobacco glyceraidehyde-3-phosphate dehydrogenases. Cell 47,7380

Shinozaki, K., Ohme, M., Tanaka, M., Wakasugi, T., Hayashida, N., Matsubayashi, T., Zaita, N., Chunwongse, J., Obokata, J., Yamaguchi-Shinozaki, K., Ohto, C., Torazawa, K., Meng, B. Y., Sugita, M., Deno, H., Kamogashira, T., Yamada, K., Kusuda, J., Takaiwa, F., Kato, A. Tohdoh. N., Shimada, H.. and Sugiura, M. (1986). The complete nucleotide sequence of the tobacco chloroplast genome: its gene organization and expression. EMBO J. 5, 2043-2049.

Soares, M. B., Schon, E., Henderson, A., Karathanasis, S. K., Cate R., Zeitlin, S., Chirgwin, J., and Efstratiadis, A. (1985). RNA-mediated gene duplication: the rat preproinsulin I gene is a functional retroposon. Mol. Cell. Biol. 5, 2090-2103.

Stern, D. B., and Lonsdale, D. M. (1982). Mitochondrial and chloroplast genomes of malze have a 12-kilobase DNA sequence in common. Nature 299, 698-702.
Stern, D. B., and Newton, K. J. (1988). Isolation of plant mitochondria RNA. In Methods for Plant Molecular Biology, A. Weissbach and $\mathrm{H}$ Weissbach, eds. (New York: Academic Press), pp. 309-317.

Takeshima, H., Joh, T., Tsuzuki, T., Shimada, K., and Matsukado $Y$. (1988). Structural organization of the mouse mitochondrial malate dehydrogenase gene. J. Mol. Biol. 200, 1-11.

Tsuzuki, T., Obaru, K., Setoyama, C., and Shimada, K. (1987). Structural organization of the mouse mitochondrial aspartate aminotransferase gene. J. Mol. Biol. 198, 21-31.

von Heijne, G., Steppuhn, J., and Herrmann, G. (1989). Domain structure of mitochondrial and chloroplast targeting peptides. Eur. J. Biochem. 180, 535-545.

Wahleithner, J. A., and Wolstenholme, D. P. (1988). Ribosomal protein $\mathbf{S 1 4}$ genes in broad bean mitochondrial DNA. Nucl. Acids Res. 16, 6897-6913.

Wahleithner, J. A., Macfarlane, J. L., and Wolstenholme, D. R. (1990). A sequence encoding a maturase-related protein in a group II intron of a plant mitochondrial nad1 gene. Proc. Nati. Acad. Sci. USA 87 , $548-552$

Watson, J. C., and Thompson, W. F. (1986). Purification and restriction endonuclease analysis of plant nuclear DNA. Meth. Enzymol. 118,5774.

Wolfe, K. H., Sharp, P. M., and Li, W.-H. (1989a). Rates of synonymous substitution in plant nuclear genes. J. Mol. Evol. 29, 208-211

Wolfe, K. H., Gouy, M., Yang, Y.-W., Sharp, P. M., and Li, W.-H. (1989b). Date of the monocot-dicot divergence estimated from chioroplast DNA sequence data. Proc. Natl. Acad. Sci. USA 86, 6201-6205.

\section{Note Added in Proot}

The work referred to as J. S. Gantt, S. L. Baldauf, P. Calie, N. Weeden and J. D. Palmer, unpublished data, can now be updated: Transfer to the nucleus of rp/22 greatly preceded its loss from the chloroplast and involved gain of an intron. EMBO J., in press. 